\title{
MEASURING SYNCHRONICITY AND CO- MOVEMENT OF BUSINESS CYCLES WITH AN APPLICATION TO THE EURO AREA
}

\author{
MARK MINK \\ JAN P.A.M. JACOBS \\ JAKOB DE HAAN
}

CESIFO WORKING PAPER NO. 2112

CATEgORY 5: Fiscal POLICY, MACROECONOMICS AND GROWTH

OCTOBER 2007

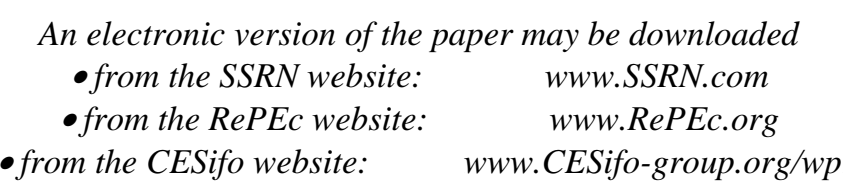




\title{
MEASURING SYNCHRONICITY AND CO- MOVEMENT OF BUSINESS CYCLES WITH AN APPLICATION TO THE EURO AREA
}

\begin{abstract}
We develop multivariate measures of synchronicity and co-movement of business cycles. In addition to synchronicity, the co-movement measure takes differences between cycle amplitudes into account that have been overlooked in most previous studies. We apply the new measures to the euro area. Synchronicity and co-movement for the region as a whole do not exhibit a clear upward tendency. Although several countries saw the similarity of their business cycle vis-'a-vis the euro area reference cycle increase, national business cycles remain fairly diverse. Changes in business cycle amplitudes cause most of the observed change in cycle co-movement.
\end{abstract}

JEL Code: E32, F02, F42.

Keywords: business cycles, synchronisation, concordance, co-movement, cycle amplitudes, euro area.

\author{
Mark Mink \\ Faculty of Economics and Business \\ University of Groningen \\ PO Box 800 \\ 9700 AV Groningen \\ The Netherlands
}

\author{
Jan P.A.M. Jacobs \\ Faculty of Economics and Business \\ University of Groningen \\ PO Box 800 \\ 9700 AV Groningen \\ The Netherlands
}

\author{
Jakob de Haan \\ Faculty of Economics and Business \\ University of Groningen \\ PO Box 800 \\ 9700 AV Groningen \\ The Netherlands \\ jakob.de.haan@rug.nl
}

September 2007

We like to thank Robert Inklaar and Jochen Mierau as well as participants in the 2006 NAKE Research Day, and The Netherlands Business Cycle Conference, Nijenrode (2007), for their comments on previous versions of the paper. 


\section{Introduction}

If business cycles in countries forming a currency union diverge considerably, the common monetary policy will not be optimal for all countries concerned ('one size does not fit all'). Whereas countries in the downward phase of the cycle prefer an expansionary monetary policy, countries in the upward phase of the cycle prefer a more restrictive policy stance. Moreover, even if cycle phases coincide perfectly, cross-country differences with respect to the amplitude of the cycle can hamper the implementation of a common monetary policy as well. Countries experiencing very large cyclical fluctuations prefer stronger monetary contractions and expansions than countries with moderate business cycle fluctuations. Since these problems might undermine support for the monetary union, a large literature has emerged on measuring the similarity of business cycle fluctuations amongst countries in the euro area. However, many of these studies yield contradicting results. ${ }^{1}$

We develop a new method to assess the similarity of business cycles that has several advantages. First, as an alternative to the widely used output gap correlations, we present a measure of cycle synchronicity that is easier to interpret. Second, we develop a cycle co-movement measure that takes differences between cycle amplitudes as well as synchronicity of cycles into account. The cycle amplitude component of business cycle similarity is generally overlooked in previous research. ${ }^{2}$ Third, both our measures are multi-

\footnotetext{
${ }^{1}$ For instance, Massmann and Mitchell (2004) find some evidence for increasing business cycle synchronicity since the 1990s. Likewise, Altavilla (2004) and Artis et al. (2004) find support for a common European cycle. However, using several alternative methodologies, Camacho et al. (2006a, 2006b) find no evidence for an increase in synchronicity or for a European business cycle. See De Haan et al. (2007) for a survey.

${ }^{2}$ Wynne and Koo (2000), Altavilla (2004), and Camacho et al. (2006b) also pay some
} 
variate and can therefore be easily applied to groups of countries. This does not require defining a reference cycle in advance since our measures identify this cycle as part of the analysis. Finally, instead of using averages over a time interval as with output gap correlations, our measures can be calculated on a per-observation basis. This can prove especially valuable in research on the determinants of business cycle synchronisation, since this literature currently relies on explaining output gap correlations calculated over a limited number of periods. ${ }^{3}$

We apply our method to the euro area for the 1970-2005 period. Our results show that substantial differences exist between countries with respect to the synchronicity and co-movement of their business cycles with the euro area reference cycle. Moreover, synchronicity and co-movement between individual countries and the region's reference cycle fluctuate substantially over time. Despite the ongoing process of European integration, synchronicity and co-movement for the region as a whole do not exhibit an upward tendency. Currently, the business cycles of several countries in the euro area are very similar to the euro area's reference cycle. However, for Finland, Greece, and Italy synchronicity and co-movement levels are rather low.

The remainder of the paper is organized as follows. Section 2 outlines our method. Section 3 describes the data, while section 4 presents our empirical results. The final section offers some concluding comments.

attention to this issue. However, they mainly focus on broad measures of cycle volatility rather than explicitly examining differences between cycles' amplitudes.

${ }^{3}$ See Frankel and Rose (1998), Kose et al. (2003), Imbs (2004), Baxter and Kouparitsas (2005), and Inklaar et al. (2007) for some representative examples. 


\section{Method}

Like most previous studies on business cycle co-movement we focus on deviations of real GDP levels from their trend value. These so-called output gaps play a central role in the monetary policy maker's reaction function, either because the policy maker explicitly aims to stabilise output fluctuations, or because the output gap is used as an indicator of future inflationary pressures. Denoting the reference output gap for the region by $g_{r}(t)$ we compute synchronicity in period $t$ between the business cycles of the $n$ countries in the sample and this reference as

$$
\varphi(t)=\frac{1}{n} \sum_{i=1}^{n} \frac{g_{i}(t) g_{r}(t)}{\left|g_{i}(t) g_{r}(t)\right|},
$$

where $g_{i}(t)$ stands for the output gap of country $i$ in period $t$. All output gaps are expressed as a percentage of trend GDP. Since the term on the right of the summation sign equals 1 when $g_{i}(t)$ and $g_{r}(t)$ have the same sign while it equals -1 when their signs are opposite, $\varphi(t)$ lies between -1 and 1 . When transformed to a uniform $[0,1]$ scale, the synchronicity measure indicates the fraction of countries with an output gap that has the same sign as the reference cycle in period $t$. Likewise, we define synchronicity between an individual country $i$ and the reference cycle in period $t$ as

$$
\varphi_{i r}(t)=\frac{g_{i}(t) g_{r}(t)}{\left|g_{i}(t) g_{r}(t)\right|}
$$

When averaged over a time interval and transformed to a uniform scaling, this measure shows the fraction of time that the output gap of country $i$ has 
the same sign as the output gap of the reference cycle. ${ }^{4}$ As a result, the measure is not only easy to interpret, but also provides a better quantification of cycle synchronicity than output gap correlations. Figure 1 illustrates this. The figure shows two deviation cycles. Although both cycles are perfectly synchronous - i.e., positive and negative output gaps coincide exactly - the correlation between the output gaps equals only 0.53. Our proposed synchronicity measure yields a value of 1 in this case as it is totally invariant to the magnitude of cycle amplitudes. ${ }^{5}$

Figure 1: Imperfect correlation despite perfect coincidence of positive and negative output gaps

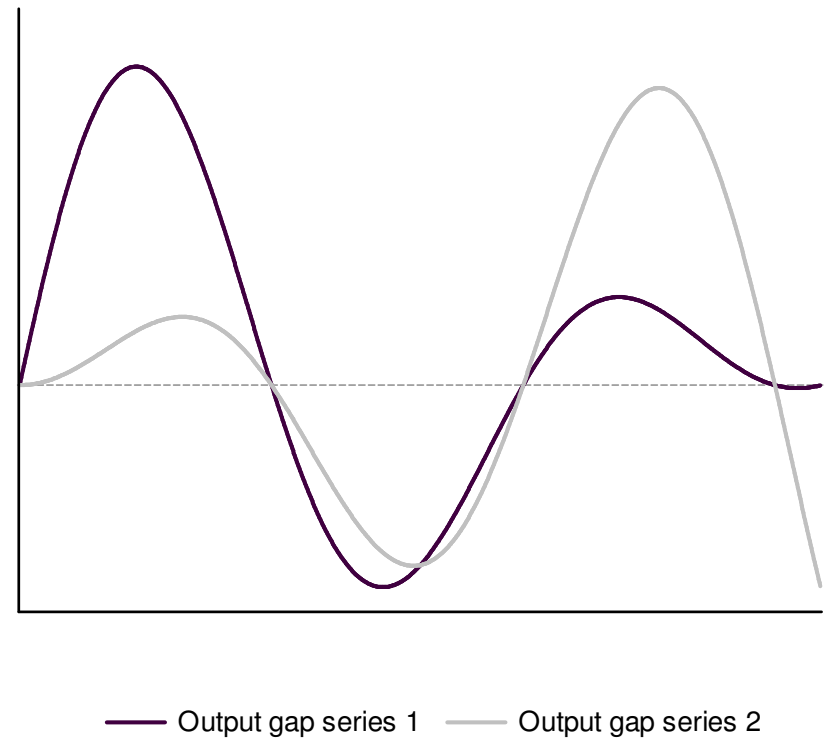

\footnotetext{
${ }^{4}$ The bivariate version of the synchronicity measure thus closely resembles the concordance index as proposed by Harding and Pagan $(2002,2006)$ for examining synchronicity between classical cycles.

${ }^{5}$ In their discussion of co-movement between classical cycles (which are defined as fluctuations in real GDP), McDermott and Scott (2000, p. 19) observe a similar issue: "correlation, as scaled covariance, mixes the concepts of duration and amplitude into one measure. The statistic is therefore not easily interpreted: a high number may be the result of significant co-movement through time, or ... the result of a single large event that is common to the two series."
} 
To examine similarity between business cycles we need to go beyond synchronicity and also pay attention to differences between cycle amplitudes. Therefore, we measure business cycle co-movement in a sample of $n$ countries in period $t$ as

$$
\gamma(t)=-\frac{\sum_{i=1}^{n}\left|g_{i}(t)-g_{r}(t)\right|}{\sum_{i=1}^{n}\left|g_{i}(t)\right|}
$$

The co-movement measure $\gamma_{i}(t)$ expresses the total distance between output gaps of the countries in the sample and the reference output gap, and scales this distance by the overall sum of these output gaps. The minus sign makes that the co-movement and business cycle similarity measure move in the same direction, i.e., an increase in the measure signals an increase in similarity. The denominator prevents the measure from being affected by an overall change in cyclical activity in the region. In a similar fashion, we define co-movement between the business cycle of country $i$ and the reference output gap in period $t$ as

$$
\gamma_{i r}(t)=-\frac{n\left|g_{i}(t)-g_{r}(t)\right|}{\sum_{i=1}^{n}\left|g_{i}(t)\right|}
$$

As is the case for the synchronicity measure, averaging co-movement between individual countries and the reference over all $n$ countries in the sample yields co-movement for the region as a whole. All the above measures can be calculated on a per-observation basis rather than as averages over time.

Having defined our synchronicity and co-movement measures, we have to decide how to specify the region's reference cycle. As Camacho et al. (2006b, p. 1689) argue, this decision is complicated by the fact that we cannot ex ante "take as given that the European cycle exists and that it coincides either with the cycle of a leading European economy, or the cycle of a weighted average 
of several European economies, or the cycle of a common factor". We adopt a statistical approach and select the cycle that lies the closest to all individual countries' cycles in the region. To this end, we set the reference gap in period $t$ equal to the median of all output gaps observed in that period. This minimises the numerator of Eq. (3) and thus maximises co-movement in the sample of countries (see Joag-Dev, 1989), while it simultaneously maximises overall synchronicity, since the median output gap by definition has the same sign as the majority of the observed output gaps. Our reference cycle thus lies the closest to all individual countries' cycles in terms of co-movement as well as synchronicity. ${ }^{6}$ Using this definition of the reference cycle ensures that the synchronicity measure defined in Eq. (1) ranges between 1 and 0, while the co-movement measure of Eq. (3) ranges between 0 and -1 . Synchronicity between the business cycle of an individual country and the reference cycle ranges between 1 and -1 , while for co-movement these values are 0 and $-n$.

\section{Data}

We apply the new measures to the euro area using time series on quarterly real GDP for eleven countries (Luxembourg and Slovenia are excluded from the sample for reasons of data availability) which in general cover the 1970.1-2005.4 period. Most statistics are obtained from the online version of the IMF International Financial Statistics database. For some of the countries time series were not available since the beginning of our sample period.

\footnotetext{
${ }^{6}$ Massmann and Mitchell (2004) adopt an alternative approach and analyse the distribution of co-movements between all possible country pairs in the region. The outcomes of such an analysis are, however, less straightforward to interpret and do not provide much guidance in identifying a potential reference cycle.
} 
These countries include Belgium (1980.1), Ireland (1997.1), the Netherlands (1977.1), and Portugal (1977.1). Statistics for the Netherlands for 1977.11998.4 are obtained from the IFS CD-ROM 2005 since the time series from the IFS online database contains an unexplained level-shift at the end of 1995. Statistics for Greece for 1970.1-2004.1 and Italy for 1970.1-1979.1 are obtained from Eurostat. We removed the 1991.1 level-shift in German GDP (which reflects the unification) by means of ratio splicing using the first annual overlap. The 1998 observations for Belgium were interpolated as the IFS database contains a measurement error. Finally, we removed seasonal fluctuations using the U.S. Census Bureau X-12-ARIMA procedure. All data are available on request.

To compute output gaps, nonparametric filtering methods, such as the high-pass filter developed by Hodrick and Prescott (1997) or the band-pass filters proposed by Baxter and King (1999) and Christiano and Fitzgerald (2003), can be used. We employ the Christiano-Fitzgerald filter and configure it to extract all cycles with a duration of 8 years or less. The ChristianoFitzgerald filter has the advantage that it does not lead to the loss of observations at the beginning and the end of the sample period. We do not remove higher frequency fluctuations from the series since cross-country differences between fluctuations with shorter periodicities can also lead to regional asymmetries. By dividing the extracted cycles by their corresponding trend components, we construct the output gap series used in the empirical analysis below. ${ }^{7}$

\footnotetext{
${ }^{7}$ Since Croux et al. (2001) show that synchronicity of cycles differs across frequency bands, we examined whether our results are sensitive to the configuration of the ChristianoFitzgerald filter. In particular, we varied the filter's upper bound between 5 and 10 year
} 


\section{Empirical analysis}

The graphs in Figure 2 show eight-year moving averages of synchronicity (left axis) and co-movement (right axis) between individual countries' business cycles and the euro area's reference cycle. The graphs show that synchronicity and co-movement levels fluctuate substantially over time and differ between countries. During the more recent years, France, Portugal, and Spain show a strong increase in synchronicity with the reference cycle, while Greece and Italy saw the synchronicity of their business cycle with the reference cycle decrease. Cycle co-movement levels increased substantially for the Netherlands and Greece. Finland had a strong temporary decrease in co-movement of its business cycle with the reference cycle at the end of the 1980s, which reflects the deep recession that hit the country due to the Nordic banking crisis and the collapse of the Soviet Union.

The final graph in the figure shows that synchronicity and co-movement levels for the euro area as a whole are much less volatile over time than the corresponding measures for individual countries. This finding reflects that idiosyncratic fluctuations cancel out in the aggregate. Moreover, synchronicity and co-movement patterns at the level of the euro area are highly similar: the correlation between them equals 0.84 . Both measures show that overall business cycle similarity does not tend to increase over time. During the last ten years, synchronicity as well as co-movement have remained virtually unchanged. Excluding all countries for which a complete time series is not

and in addition extracted fluctuations with duration between 1.5 and 8 years. Although this indeed affected the synchronicity and co-movement patterns, our main conclusions do not change. All results are available on request. 
Figure 2: Synchronicity and co-movement of business cycles in the euro area
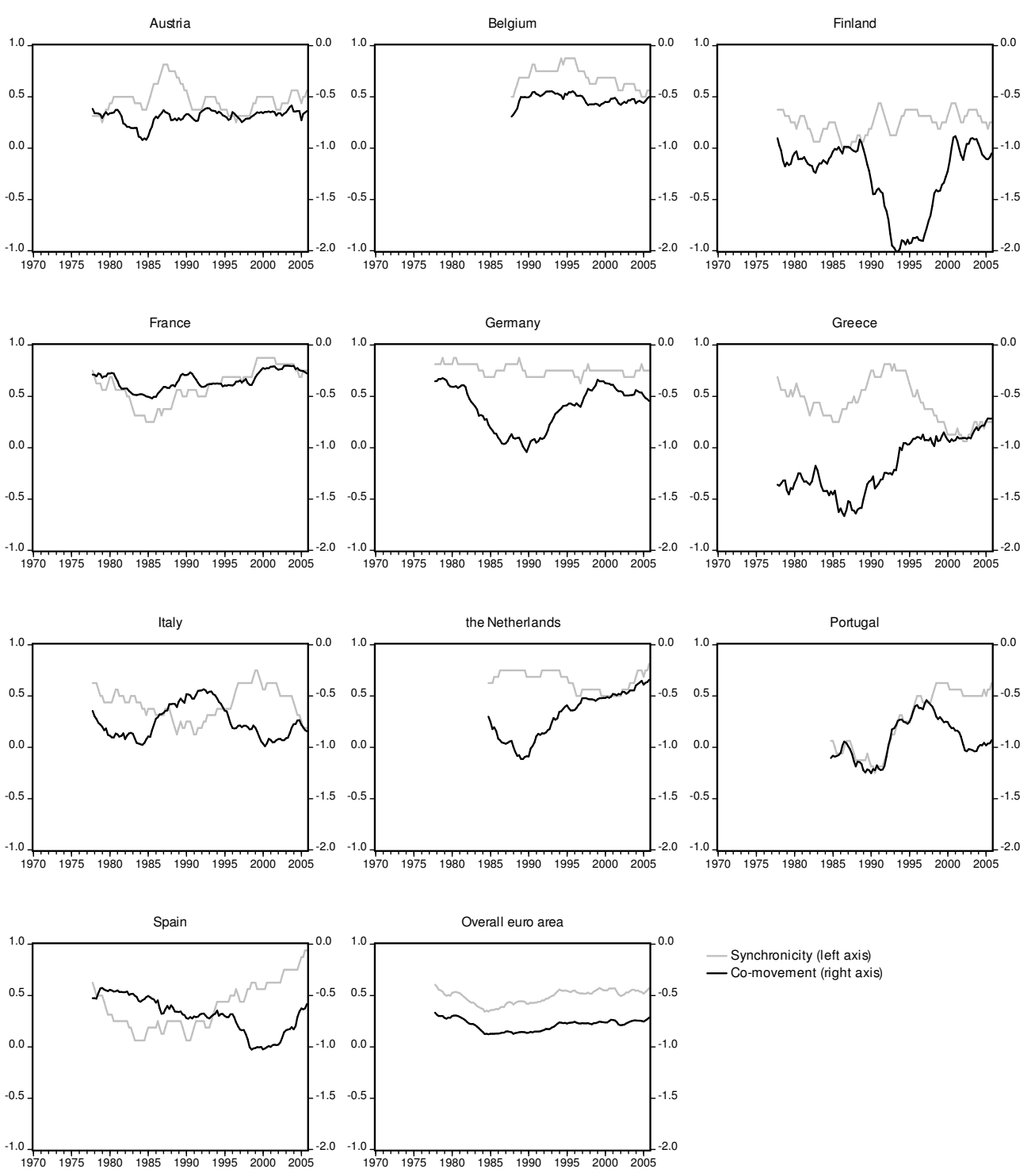
available, yields similar results. Allowing for leads or lags between business cycles does not change our conclusions (results are available on request).

Although in the graph for the euro area as a whole synchronicity and co-movement show similar developments, the graphs for the individual countries tell a different story. The correlation between the synchronicity and co-movement patterns ranges from -0.73 (Greece) to 0.80 (Portugal) with an average value of $0.09 .^{8}$ This finding further illustrates that synchronicity and co-movement are different concepts. To gain more insight in the nature of this difference, we decompose the co-movement measure into a synchronicity and an amplitude similarity component in the Appendix. The first component measures to what extent deviations from perfect synchronicity affect cycle co-movement, while the second does the same for deviations from perfect amplitude similarity. Although the amplitude component of cycle co-movement is somewhat smaller in magnitude than the synchronicity component, changes therein are the main driving force behind changes in cycle co-movement.

We performed a simulation analysis to find out how likely it is that the reported synchronicity and co-movement levels are observed when the business cycles in our sample fluctuate independently from one another. To this end, we regressed the output gaps in our sample on an $\mathrm{AR}(1)$ component. This yielded coefficient estimates ranging between 0.48 and 0.83 , and standard er-

\footnotetext{
${ }^{8}$ Since many authors use output gap correlations as a measure of business cycle synchronicity, we computed such correlations as well and compared them with the results for our synchronicity measure. It turned out that correlation between both was rather low: values fluctuated between 0.45 (Belgium) and 0.96 (Portugal), and equalled 0.69 on average. When we repeated this analysis using a band-pass filter with upper bound equal to 1.5 years to extract the output gaps, these values fell to $0.40,0.93$, and 0.60 , respectively. Results are available on request.
} 
Table 1: Five-percent critical values for synchronicity and co-movement

\begin{tabular}{cllllllllllll}
\multicolumn{1}{c}{ Number of countries in the sample } \\
\cline { 2 - 11 } & 2 & 3 & 4 & 5 & 6 & 7 & 8 & 9 & 10 & 11 \\
\hline Synchronicity & & & & & & & & & & \\
Overall & 0.69 & 0.63 & 0.50 & 0.48 & 0.42 & 0.40 & 0.36 & 0.35 & 0.33 & 0.32 \\
Ind. country & - & 0.81 & 0.69 & 0.69 & 0.63 & 0.63 & 0.63 & 0.63 & 0.56 & 0.56 \\
& & & & & & & & & & \\
Co-movement & & & & & & & & & & \\
Overall & -0.60 & -0.64 & -0.78 & -0.79 & -0.84 & -0.85 & -0.88 & -0.88 & -0.90 & -0.91 \\
Ind. country & - & -0.35 & -0.48 & -0.39 & -0.44 & -0.40 & -0.42 & -0.40 & -0.42 & -0.40 \\
\hline
\end{tabular}

rors of the regression between 0.005 and 0.014 . On the basis of these results, we generated output gap sequences as first-order autoregressive processes with $\mathrm{AR}(1)$ parameters randomly drawn from the $[0.48,0.83]$ interval, and disturbances drawn from a zero-mean normal distribution where the standard deviation was randomly selected from the $[0.005,0.014]$ interval. Since the length of our moving window equals thirty-two quarters, we generated output gap series of 532 observations and deleted the first 500 data points. Then, we computed synchronicity and co-movement between groups of these sequences for 10,000 simulations. Table 1 lists the five-percent critical values that we obtained for group sizes between two and eleven countries.

Since the number of countries in the sample ranges between 7 and 11 , synchronicity and co-movement between individual countries and the reference can be considered significant when their values are higher than 0.6 and -0.4 respectively. For many countries in the area this is never the case; especially co-movement levels often turn out to be insignificant. In contrast, synchronicity and co-movement for the euro area as a whole are always significant during the 1970.1-2005.4 period. Hence, although countries experience substantial idiosyncratic business cycle fluctuations, their cycles share a com- 
mon component that can be interpreted as a euro area business cycle. ${ }^{9}$ Figure 3 shows that this reference cycle also has the visual appearance of an 'actual' business cycle.

Figure 3: The euro area's reference cycle

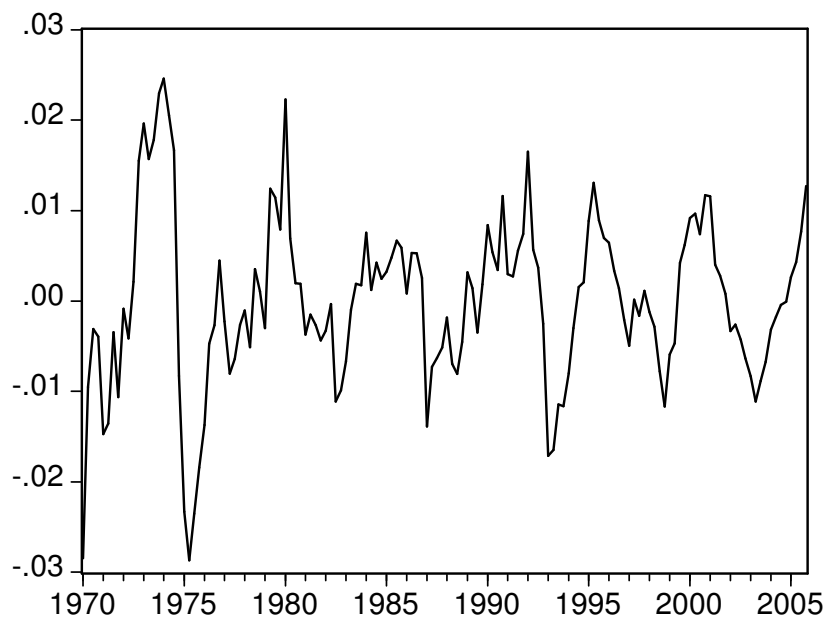

To examine business cycle similarity under the regime of the monetary union, the second and the third column of Table 2 report synchronicity and co-movement of the business cycles of the countries in the currency union with the reference cycle during the 1998-2005 period. The reported synchronicity outcomes are easier to interpret when we transform them to a uniform $[0,1]$ scale. The value for synchronicity in the euro area indicates that on average $100 \% \times(0.57+1) / 2=78.5 \%$ of the countries have an output gap with the same sign as the output gap of the reference cycle. In addition, the co-movement statistic for the region as a whole shows that the distance

\footnotetext{
${ }^{9}$ Of course, we cannot rule out the possibility that the significant synchronicity and co-movement levels in our sample are the result of a common cycle in a broader sample of countries such as the OECD or even the world, instead of being limited to countries in the currency union alone.
} 
Table 2: Cycle synchronicity and co-movement for the 1998 - 2005 period

\begin{tabular}{lcccc} 
& \multicolumn{2}{c}{ Reference cycle } & \multicolumn{2}{c}{ Aggregate cycle } \\
\cline { 2 - 5 } Country & Synchronicity & Co-movement & Synchronicity & Co-movement \\
\hline Austria & 0.56 & $\mathbf{- 0 . 6 4}$ & 0.56 & -1.05 \\
Belgium & 0.56 & $\mathbf{- 0 . 5 0}$ & 0.44 & -0.73 \\
Finland & 0.25 & -1.05 & 0.25 & -1.40 \\
France & $\mathbf{0 . 7 5 *}$ & $\mathbf{- 0 . 2 8}$ & $\mathbf{0 . 7 5}$ & $\mathbf{- 0 . 4 0}$ \\
Germany & $\mathbf{0 . 7 5 *}$ & $\mathbf{- 0 . 5 5}$ & $\mathbf{0 . 8 8}$ & $\mathbf{- 0 . 4 2}$ \\
Greece & 0.25 & -0.72 & 0.13 & -1.03 \\
Ireland & $0.63^{*}$ & -1.43 & 0.50 & -1.97 \\
Italy & 0.19 & -0.84 & 0.31 & -0.74 \\
Netherlands & $\mathbf{0 . 8 1 *}$ & $\mathbf{- 0 . 3 4}$ & $\mathbf{0 . 9 4}$ & $\mathbf{- 0 . 5 5}$ \\
Portugal & $\mathbf{0 . 6 3}$ & -0.93 & 0.63 & -1.05 \\
Spain & $\mathbf{0 . 9 4}$ & $\mathbf{- 0 . 5 8}$ & $\mathbf{0 . 8 1}$ & -0.87 \\
\hline Euro area & $0.57^{*}$ & $-0.71^{*}$ & 0.67 & -0.64 \\
\hline
\end{tabular}

Notes: * denotes significance at the five percent level based on the critical values of Table 1 which are computed for similarity with respect to the reference cycle. Statistics printed in bold indicate that the country performs above the euro area average. This average is reported in the bottom row, for the last two columns a weighted average is computed on the basis of countries' GDP size.

between output gaps on average equals $71 \%$ of the total magnitude of cyclical fluctuations in the region. Furthermore, for many individual countries synchronicity levels are significant, while we find significant co-movement statistics only for France and the Netherlands. Especially the business cycles of Finland, Greece, and Italy differ from those of other countries in the area. Finally, synchronicity and co-movement levels for France, Germany, the Netherlands and Spain structurally lie above the euro area average.

In setting its monetary policy the European Central Bank (ECB) focuses on the euro area as a whole and thus will grant more weight to larger euro area countries (ECB 2004, p.51). The last two columns in Table 2 therefore report synchronicity and co-movement between countries' business cycles and 
the euro area aggregate cycle. The latter is based on the cycle in euro area output. ${ }^{10}$ The figures in the bottom row show that the weighted averages of synchronicity and co-movement with the euro area's aggregate cycle are larger than the averages of synchronicity and co-movement with the reference cycle. The standard deviations of synchronicity and co-movement towards the aggregate cycle equal 0.27 and 0.46 , while for the reference cycle these values amount to 0.25 and 0.27 . While it was to be expected that similarity with the aggregate cycle is lower than similarity with the reference cycle (as we defined the reference cycle as the cycle that lies the closest to all individual countries' cycles), also cross-country differences in cycle similarity increase when the aggregate cycle is considered. Countries with business cycles that are relatively close to the aggregate cycle are France, Germany, and the Netherlands. The opposite is the case for especially Finland, Greece, and Italy. Asymmetries such as these may hamper the ECB in setting a common monetary policy that is optimal for all countries in the euro area. Since our results in Figure 2 show that there is no upward tendency in synchronicity and co-movement since the start of the currency union, it remains to be seen whether these disparities will disappear.

\footnotetext{
${ }^{10}$ Using data from the January 2007 version of the Total Economy Database maintained by The Conference Board and the Groningen Growth and Development Centre (see http://www.ggdc.net), we constructed country specific weights as $\varpi_{i}(t)=$ $y_{i}(t) / \sum_{i=1}^{n} y_{i}(t)$ where $y_{i}(t)$ denotes real GDP of country $i$ in period $t$. We define the aggregate output gap as $g_{a}(t)=\sum_{i=1}^{n} \varpi_{i}(t) g_{i}(t)$, and we computed synchronicity and comovement towards this cycle on the basis of Eqs. (1) to (4). We modified these equations by inserting a parameter $\varpi_{i}(t)$ after each and every summation sign, and by removing the parameters $n$ and $1 / n$ from the equations altogether (of course, with exceptions for those in the superscript of the summation signs). Note that the lower bounds and the critical values that we derived for the measures do not apply anymore.
} 


\section{Conclusion}

If national business cycles in a currency union diverge considerably, the common monetary policy will not be optimal for all countries concerned. Since this might undermine support for the monetary union, a large literature has emerged examining the similarity of business cycle fluctuations of countries in the euro area. We add to this literature by proposing a new, multivariate measure of synchronicity of business cycles. In addition, we introduce a multivariate cycle co-movement measure, which takes differences between cycle amplitudes into account that have been largely overlooked by previous research. Finally, our measures suggest a simple and intuitive method to calculate a region's reference cycle.

In an empirical analysis of developments in the euro area during the 19702005 period, we find that overall synchronicity and co-movement have always been statistically significant. However, synchronicity and co-movement between business cycles of individual countries and the reference cycle fluctuate over time. Changes in cycle co-movement are mainly caused by changes in amplitude similarity between business cycles. Under the regime of the monetary union, synchronicity and co-movement levels are significant for a limited number of countries. Especially the cycles of France, Germany, and the Netherlands are similar to the rest of the region, while Finland, Greece, and Italy perform substantially worse in this respect. When we take into account that economic developments in larger countries get more weight when the ECB decides upon its monetary policy, heterogeneity within the region increases. As there is no upward tendency in synchronicity and co-movement 
levels, it remains to be seen whether future developments in the euro area will aggravate or alleviate these disparities. 


\section{Appendix: Decomposition of cycle co-movement}

To decompose the co-movement measure in a synchronicity and an amplitude similarity component we use a result discussed by Patel and Read (1982, p. 34). These authors show that if a random variable $X$ is normally distributed with mean $\mu_{x}$ and standard deviation $\sigma_{x}$, the variable $|X|$ has a folded normal distribution with expected value

$$
E|X|=\sigma_{x} \sqrt{\frac{2}{\pi}} \exp \left(-\frac{\mu_{x}^{2}}{2 \sigma_{x}^{2}}\right)+\mu_{x}\left(1-2 \Phi\left[-\frac{\mu_{x}}{\sigma_{x}}\right]\right)
$$

where $\Phi(\cdot)$ denotes the cumulative distribution function of a standard normal distribution. Hence, if two output gap series $g_{i}$ and $g_{r}$ are normally distributed with expected values $\mu_{i}$ and $\mu_{r}$ and standard deviations $\sigma_{i}$ and $\sigma_{r}$, then the expected value of the absolute difference between these series is given by

$$
E\left|g_{i}-g_{r}\right|=\sigma_{i-r} \sqrt{\frac{2}{\pi}} \exp \left(-\frac{\mu_{i-r}^{2}}{2 \sigma_{i-r}^{2}}\right)+\mu_{i-r}\left(1-2 \Phi\left[-\frac{\mu_{i-r}}{\sigma_{i-r}}\right]\right),
$$

where $\mu_{i-r}=\mu_{i}-\mu_{r}$. The standard deviation of the difference between $g_{i}$ and $g_{r}$ is defined as

$$
\sigma_{i-r}=\sqrt{\sigma_{i}^{2}+\sigma_{r}^{2}-2 \rho_{i r} \sigma_{i} \sigma_{r}}
$$

where $\rho_{i r}$ denotes the correlation between series $g_{i}$ and $g_{r}$.

To examine to what extent the distance between output gap series is caused by deviations from perfect correlation, we compute the value of Eq. (A.2) under the restriction that the amplitude of output gap series $g_{i}$ is 
identical to the amplitude of the reference output gap series $g_{r}$. This restriction implies that $E\left|g_{i}\right|=E\left|g_{r}\right|$, which according to Eq. (A.1) implies that $\mu_{i}=\mu_{r}$ and $\sigma_{i}=\sigma_{r}$. Under these conditions, Eq. (A.2) reduces to

$$
E\left|g_{i}-g_{r}\right|=\sqrt{4\left(1-\rho_{i r}\right) \sigma_{r}^{2} / \pi}
$$

In view of our definition of cycle co-movement in Eq. (3) in the main text, we can use Eq. (A.4) to define the correlation component of cycle co-movement as

$$
\gamma^{\rho}=-\frac{\sum_{i=1}^{n} \sqrt{4\left(1-\rho_{i r}\right) \sigma_{r}^{2} / \pi}}{\sum_{i=1}^{n} E\left|g_{i}\right|},
$$

which equals zero when $\rho_{i r}=1$. In a similar manner, we can use Eq. (A.2) to approximate the co-movement measure defined in Eq. (3). Subtracting Eq. (A.5) from this approximation then yields the amplitude similarity component of cycle co-movement. This component indicates to what extent deviations from perfect cycle co-movement are caused by deviations from perfect amplitude similarity.

Figure 4 presents graphs for the (approximation of the) co-movement measure and for the correlation component thereof. The amplitude similarity component equals the difference between these two. Eyeballing the co-movement patterns suggests that approximating co-movement on the basis of Eq. (A.2) leads to results that are quite similar to those reported in Figure 2. This finding is confirmed by the correlation between both comovement measures, which ranges from 0.77 (Spain) to 0.98 (Germany), with an average of 0.91 .

The correlation between the correlation component reported in Figure 2 
Figure 4: Decomposition of cycle co-movement
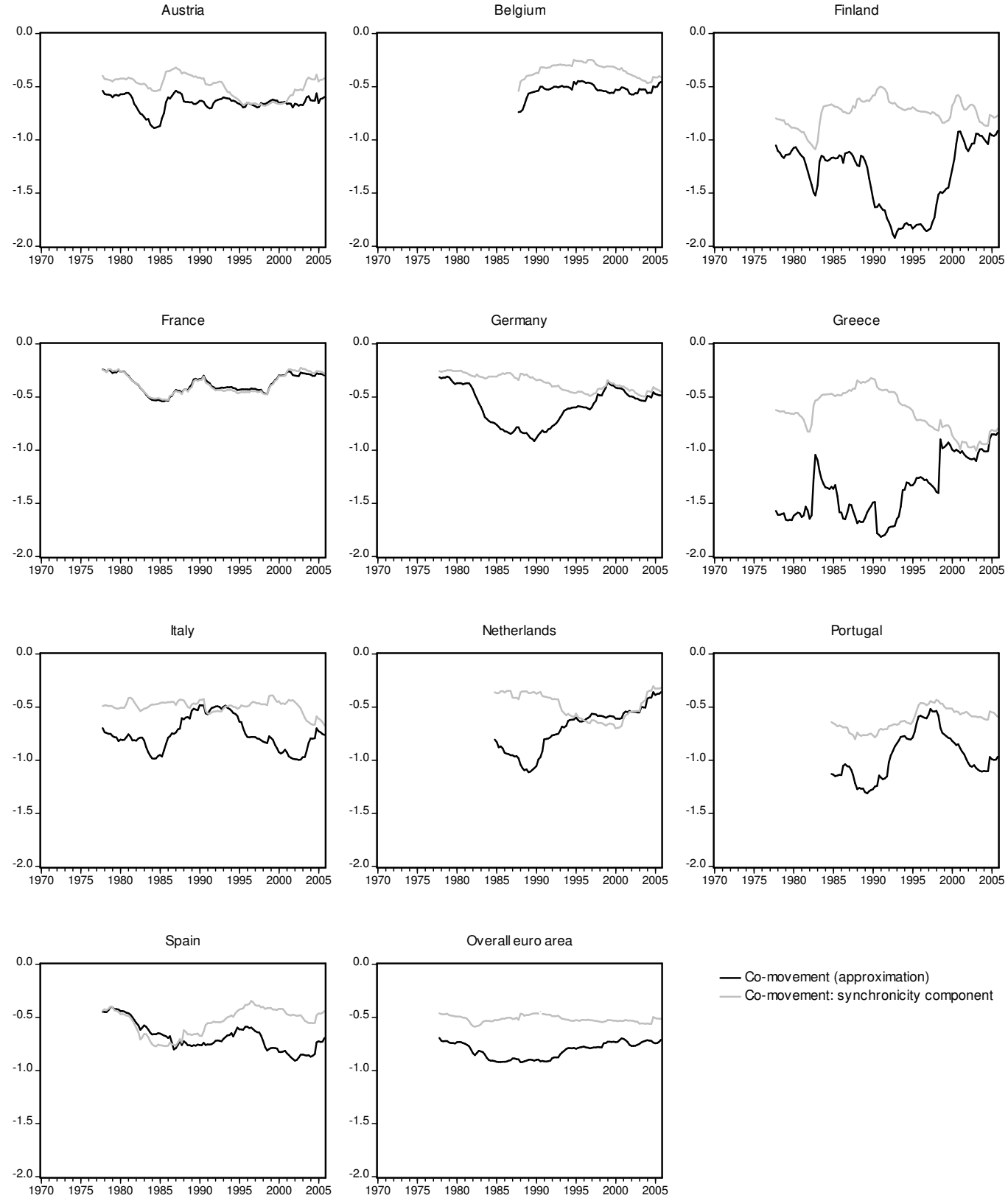
and output gap correlations $\rho_{i r}$ ranges between 0.45 (Belgium) and 0.96 (Portugal), with an average of 0.69. Since Eq. (A.4) shows that the relationship between both measures is non-linear, this result suggests that the correlation component of cycle co-movement indeed properly picks up changes in cycle correlation. Moreover, the correlation between the correlation component and cycle synchronicity patterns as reported in Figure 2 is only marginally lower: it ranges between 0.17 (Finland) and 0.87 (Portugal) with an average value of 0.62 . Replacing output gap correlation $\rho_{i r}$ by output gap synchronicity $\varphi_{i r}$ in Eqs. (A.3) and (A.5) leads to results that are qualitatively similar to the ones reported in Figure 4. Therefore, for the present analysis, we will - with caution - interpret the correlation component as a synchronicity component.

The amplitude similarity component of cycle co-movement can be obtained as the difference between co-movement and the synchronicity component. As the graphs show, this difference often fluctuates substantially over time and is generally more volatile than the synchronicity component. It turns out these fluctuations quite accurately reflect fluctuations in similarities between business cycle amplitudes. We examined this by comparing them with fluctuations in the size of $-|E| g_{i}|-E| g_{r}||$, which we computed within an eight year moving window as well. The correlation between this simple measure of amplitude similarity and the amplitude similarity component of cycle co-movement ranges between 0.77 (Italy) and 0.97 (Germany), with an average value of 0.88 .

The correlation between the synchronicity component and the amplitude similarity component is fairly low and ranges from -0.89 (Greece) to -0.05 
(Portugal) with an average value of -0.5 . Moreover, the correlation between the amplitude similarity component and total cycle co-movement lies between 0.27 (Belgium) and 0.95 (Greece) with an average of 0.77 . Hence, the difference between the synchronicity and co-movement patterns in Figure 2 is caused by the amplitude similarity component of cycle co-movement. Even though the synchronicity component is larger in magnitude, fluctuations in cycle co-movement are thus mainly driven by changes in amplitude similarity between business cycles. 


\section{Acknowledgements}

We like to thank Robert Inklaar and Jochen Mierau as well as participants in the 2006 NAKE Research Day, and The Netherlands Business Cycle Conference, Nijenrode (2007), for their comments on previous versions of the paper. 


\section{References}

Altavilla, C. (2004). Do EMU Members Share the Same Business Cycle? Journal of Common Market Studies 42: 869-96.

Artis, M.J., H.M. Krolzig and J. Toro (2004). The European Business Cycle. Oxford Economic Papers 56: 1-44.

Baxter, M. and R.G. King (1999). Measuring Business Cycles: Approximate Band-Pass Filters for Economic Time Series. The Review of Economics and Statistics 81: 575-93.

Baxter, M. and M. Kouparitsas (2005). Determinants of Business Cycle Co-movement: A Robust Analysis. Journal of Monetary Economics 52: $113-57$.

Camacho, M., G. Perez-Quiros and L. Saiz (2006a). Do European Business Cycles Look Like One? Bank of Spain Working Paper 0518.

Camacho, M., G. Perez-Quiros and L. Saiz (2006b). Are European Business Cycles Close Enough to be Just One? Journal of Economic Dynamics and Control 30: 1687-1706.

Christiano, L. and T.J. Fitzgerald (2003). The Band-Pass Filter. International Economic Review 44: 435-65.

Croux, C., M. Forni and L. Reichlin (2001). A Measure for Comovement of Economic Variables: Theory and Empirics. The Review of Economics and Statistics 83: 232-41. 
De Haan, J., R. Inklaar and R.M. Jong-a-Pin (2007). Will Business Cycles in the Euro Area Converge? A Critical Survey of Empirical Research. Journal of Economic Surveys, forthcoming.

ECB (2004). The Monetary Policy of the ECB. Frankfurt am Main: European Central Bank.

Frankel, J.A. and A.K. Rose (1998). The Endogeneity of the Optimum Currency Area Criteria. The Economic Journal 108: 1009-25.

Harding, D. and A. Pagan (2002). Dissecting the Cycle: A Methodological Investigation. Journal of Monetary Economics 49: 365-81.

Harding, D. and A. Pagan (2006). Synchronization of Cycles. Journal of Econometrics 132: 59-79.

Hodrick, R.J. and E.C. Prescott (1997). Postwar U.S. Business Cycles: An Empirical Investigation. Journal of Money, Credit, and Banking 29: $1-16$.

Imbs, J. (2004). Trade, Finance, Specialization and Synchronization. The Review of Economics and Statistics 86: 723-34.

Inklaar, R, R.M. Jong-A-Pin and J. De Haan (2007). Trade and Business Cycle Cynchronization in OECD Countries: A Re-examination. European Economic Review, forthcoming.

Joag-Dev, K. (1989). MAD Property of a Median: A Simple Proof. The American Statistician 43:26-7. 
Kose, M.A., E.S. Prasad and M.E. Terrones (2003). How Does Globalization Affect the Synchronization of Business Cycles? American Economic Review 93: 57-62.

Massmann, M. and J. Mitchell (2004). Reconsidering the Evidence: Are Eurozone Business Cycles Converging? Journal of Business Cycle Measurement and Analysis 1: 275-308.

McDermott, C.J. and A. Scott (2000). Concordance in Business Cycles. IMF Working Paper 00/37.

Patel, J.K. and C.B. Read (1982). Handbook of the Normal Distribution. New York: Marcel Dekker, Inc.

Wynne, M.A. and J. Koo (2000). Business Cycles Under Monetary Union: A Comparison of the EU and US. Economica 67: 347-74. 


\section{CESifo Working Paper Series}

for full list see www.cesifo-group.org/wp

(address: Poschingerstr. 5, 81679 Munich, Germany, office@cesifo.de)

2048 Daniel Becker and Michael Rauscher, Fiscal Competition in Space and Time: An Endogenous-Growth Approach, July 2007

2049 Yannis M. Ioannides, Henry G. Overman, Esteban Rossi-Hansberg and Kurt Schmidheiny, The Effect of Information and Communication Technologies on Urban Structure, July 2007

2050 Hans-Werner Sinn, Please Bring me the New York Times - On the European Roots of Richard Abel Musgrave, July 2007

2051 Gunther Schnabl and Christian Danne, A Role Model for China? Exchange Rate Flexibility and Monetary Policy in Japan, July 2007

2052 Joseph Plasmans, Jorge Fornero and Tomasz Michalak, A Microfounded Sectoral Model for Open Economies, July 2007

2053 Vesa Kanniainen and Panu Poutvaara, Imperfect Transmission of Tacit Knowledge and other Barriers to Entrepreneurship, July 2007

2054 Marko Koethenbuerger, Federal Tax-Transfer Policy and Intergovernmental PreCommitment, July 2007

2055 Hendrik Jürges and Kerstin Schneider, What Can Go Wrong Will Go Wrong: Birthday Effects and Early Tracking in the German School System, July 2007

2056 Bahram Pesaran and M. Hashem Pesaran, Modelling Volatilities and Conditional Correlations in Futures Markets with a Multivariate t Distribution, July 2007

2057 Walter H. Fisher and Christian Keuschnigg, Pension Reform and Labor Market Incentives, July 2007

2058 Martin Altemeyer-Bartscher, Dirk T. G. Rübbelke and Eytan Sheshinski, Policies to Internalize Reciprocal International Spillovers, July 2007

2059 Kurt R. Brekke, Astrid L. Grasdal and Tor Helge Holmås, Regulation and Pricing of Pharmaceuticals: Reference Pricing or Price Cap Regulation?, July 2007

2060 Tigran Poghosyan and Jakob de Haan, Interest Rate Linkages in EMU Countries: A Rolling Threshold Vector Error-Correction Approach, July 2007

2061 Robert Dur and Klaas Staal, Local Public Good Provision, Municipal Consolidation, and National Transfers, July 2007

2062 Helge Berger and Anika Holler, What Determines Fiscal Policy? Evidence from German States, July 2007 
2063 Ernesto Reuben and Arno Riedl, Public Goods Provision and Sanctioning in Privileged Groups, July 2007

2064 Jan Hanousek, Dana Hajkova and Randall K. Filer, A Rise by Any Other Name? Sensitivity of Growth Regressions to Data Source, July 2007

2065 Yin-Wong Cheung and Xing Wang Qian, Hoarding of International Reserves: Mrs Machlup’s Wardrobe and the Joneses, July 2007

2066 Sheilagh Ogilvie, 'Whatever Is, Is Right'?, Economic Institutions in Pre-Industrial Europe (Tawney Lecture 2006), August 2007

2067 Floriana Cerniglia and Laura Pagani, The European Union and the Member States: Which Level of Government Should Do what? An Empirical Analysis of Europeans' Preferences, August 2007

2068 Alessandro Balestrino and Cinzia Ciardi, Social Norms, Cognitive Dissonance and the Timing of Marriage, August 2007

2069 Massimo Bordignon, Exit and Voice. Yardstick versus Fiscal Competition across Governments, August 2007

2070 Emily Blanchard and Gerald Willmann, Political Stasis or Protectionist Rut? Policy Mechanisms for Trade Reform in a Democracy, August 2007

2071 Maarten Bosker and Harry Garretsen, Trade Costs, Market Access and Economic Geography: Why the Empirical Specification of Trade Costs Matters, August 2007

2072 Marco Runkel and Guttorm Schjelderup, The Choice of Apportionment Factors under Formula Apportionment, August 2007

2073 Jay Pil Choi, Tying in Two-Sided Markets with Multi-Homing, August 2007

2074 Marcella Nicolini, Institutions and Offshoring Decision, August 2007

2075 Rainer Niemann, The Impact of Tax Uncertainty on Irreversible Investment, August 2007

2076 Nikitas Konstantinidis, Gradualism and Uncertainty in International Union Formation, August 2007

2077 Maria Bas and Ivan Ledezma, Market Access and the Evolution of within Plant Productivity in Chile, August 2007

2078 Friedrich Breyer and Stefan Hupfeld, On the Fairness of Early Retirement Provisions, August 2007

2079 Scott Alan Carson, Black and White Labor Market Outcomes in the $19^{\text {th }}$ Century American South, August 2007 
2080 Christian Bauer, Paul De Grauwe and Stefan Reitz, Exchange Rates Dynamics in a Target Zone - A Heterogeneous Expectations Approach, August 2007

2081 Ana Rute Cardoso, Miguel Portela, Carla Sá and Fernando Alexandre, Demand for Higher Education Programs: The Impact of the Bologna Process, August 2007

2082 Christian Hopp and Axel Dreher, Do Differences in Institutional and Legal Environments Explain Cross-Country Variations in IPO Underpricing?, August 2007

2083 Hans-Werner Sinn, Pareto Optimality in the Extraction of Fossil Fuels and the Greenhouse Effect: A Note, August 2007

2084 Robert Fenge, Maximilian von Ehrlich and Matthias Wrede, Fiscal Competition, Convergence and Agglomeration, August 2007

2085 Volker Nitsch, Die Another Day: Duration in German Import Trade, August 2007

2086 Kam Ki Tang and Jie Zhang, Morbidity, Mortality, Health Expenditures and Annuitization, August 2007

2087 Hans-Werner Sinn, Public Policies against Global Warming, August 2007

2088 Arti Grover, International Outsourcing and the Supply Side Productivity Determinants, September 2007

2089 M. Alejandra Cattaneo and Stefan C. Wolter, Are the Elderly a Threat to Educational Expenditures?, September 2007

2090 Ted Bergstrom, Rod Garratt and Damien Sheehan-Connor, One Chance in a Million: Altruism and the Bone Marrow Registry, September 2007

2091 Geraldo Cerqueiro, Hans Degryse and Steven Ongena, Rules versus Discretion in Loan Rate Setting, September 2007

2092 Henrik Jacobsen Kleven, Claus Thustrup Kreiner and Emmanuel Saez, The Optimal Income Taxation of Couples as a Multi-Dimensional Screening Problem, September 2007

2093 Michael Rauber and Heinrich W. Ursprung, Life Cycle and Cohort Productivity in Economic Research: The Case of Germany, September 2007

2094 David B. Audretsch, Oliver Falck and Stephan Heblich, It's All in Marshall: The Impact of External Economies on Regional Dynamics, September 2007

2095 Michael Binder and Christian J. Offermanns, International Investment Positions and Exchange Rate Dynamics: A Dynamic Panel Analysis, September 2007

2096 Louis N. Christofides and Amy Chen Peng, Real Wage Chronologies, September 2007 
2097 Martin Kolmar and Andreas Wagener, Tax Competition with Formula Apportionment: The Interaction between Tax Base and Sharing Mechanism, September 2007

2098 Daniela Treutlein, What actually Happens to EU Directives in the Member States? - A Cross-Country Cross-Sector View on National Transposition Instruments, September 2007

2099 Emmanuel C. Mamatzakis, An Analysis of the Impact of Public Infrastructure on Productivity Performance of Mexican Industry, September 2007

2100 Gunther Schnabl and Andreas Hoffmann, Monetary Policy, Vagabonding Liquidity and Bursting Bubbles in New and Emerging Markets - An Overinvestment View, September 2007

2101 Panu Poutvaara, The Expansion of Higher Education and Time-Consistent Taxation, September 2007

2102 Marko Koethenbuerger and Ben Lockwood, Does Tax Competition Really Promote Growth?, September 2007

2103 M. Hashem Pesaran and Elisa Tosetti, Large Panels with Common Factors and Spatial Correlations, September 2007

2104 Laszlo Goerke and Marco Runkel, Tax Evasion and Competition, September 2007

2105 Scott Alan Carson, Slave Prices, Geography and Insolation in $19^{\text {th }}$ Century AfricanAmerican Stature, September 2007

2106 Wolfram F. Richter, Efficient Tax Policy Ranks Education Higher than Saving, October 2007

2107 Jarko Fidrmuc and Roman Horváth, Volatility of Exchange Rates in Selected New EU Members: Evidence from Daily Data, October 2007

2108 Torben M. Andersen and Michael Svarer, Flexicurity - Labour Market Performance in Denmark, October 2007

2109 Jonathan P. Thomas and Tim Worrall, Limited Commitment Models of the Labor Market, October 2007

2110 Carlos Pestana Barros, Guglielmo Maria Caporale and Luis A. Gil-Alana, Identification of Segments of European Banks with a Latent Class Frontier Model, October 2007

2111 Felicitas Nowak-Lehmann D., Sebastian Vollmer and Immaculada Martínez-Zarzoso, Competitiveness - A Comparison of China and Mexico, October 2007

2112 Mark Mink, Jan P.A.M. Jacobs and Jakob de Haan, Measuring Synchronicity and Comovement of Business Cycles with an Application to the Euro Area, October 2007 